\title{
Temperature: Diet Interactions Affect Survival through Foraging Behavior in a Bromeliad-Dwelling Predator
}

\author{
Olivier Dézerald ${ }^{1,7}$, Régis Céréghino ${ }^{2,3}$, Bruno Corbara ${ }^{4,5}$, Alain Dejean ${ }^{1,2}$, and Céline Leroy ${ }^{6}$ \\ ${ }^{1}$ Ecologie des Forêts de Guyane (UMR-CNRS 8172), CNRS, Campus Agronomique, F-97379, Kourou Cedex, France \\ ${ }^{2}$ UPS Laboratoire Ecologie Fonctionnelle et Environnement (ECOLAB), Université de Toulouse, INP, 31062, Toulouse, France \\ ${ }^{3}$ ECOLAB (UMR-CNRS 5245), CNRS, 118 Route de Narbonne, 31062, Toulouse, France \\ ${ }^{4}$ Clermont Université, Université Blaise Pascal, BP 10448, 63000, Clermont-Ferrand, France \\ ${ }^{5}$ Laboratoire Microorganismes: Génome et Environnement (UMR-CNRS 6023), CNRS, 63177, Aubière, France \\ ${ }^{6}$ UMR AMAP (botAnique et Modélisation de l'Architecture des Plantes et des végétations), IRD, Boulevard de la Lironde, TA A-51/PS2, \\ 34398, Montpellier Cedex 5, France
}

\begin{abstract}
Temperature, food quantity and quality play important roles in insect growth and survival, influencing population dynamics as well as interactions with other community members. However, the interaction between temperature and diet and its ecological consequences have been poorly documented. Toxorbynchites are well-known biocontrol agents for container-inhabiting mosquito larvae. We found that Toxorbynchites haemorrhoidalis larvae (Diptera: Culicidae) inhabiting water-filled rosettes of tank bromeliads catch and eat prey of both aquatic (mosquito larvae) and terrestrial origin (ants), using distinct predatory methods. They carried out frontal attacks on ants, but ambushed mosquito larvae. In choice tests, T. haemorrboidalis favored terrestrial prey. Temperature had a significant effect on predator development and survival through its interaction with diet, but did not alter the preference for ants. T. haemorrhoidalis larvae emerged quickly when fed only mosquito larvae, whereas all individuals died before pupation when fed only ants. We conclude that behavioral factors (i.e., attraction to ants that disturb the surface of the water) overtake physiological factors (i.e., the adverse outcome of elevated temperature and an ant-based diet) in determining a predator's response to temperature:diet interactions. Finally, because T. haemorrhoidalis larvae preferentially feed on terrestrial insects in tank bromeliads, mosquito larvae may indirectly benefit from predation release.
\end{abstract}

Abstract in French is available with online material.

Key words: biocontrol agent; development; French Guiana; selective feeding behavior; tank bromeliad; Toxorbynchites haemorrboidalis.

ECOLOGICAL COMMUNITIES FORM COMPLEX NETWORKS, AMONG WHICH FOOD WEBS ARE THE MOST STUDIED. Most predatory species are thought to modify their linkage patterns with other species following changes in relative density or biomass (Kondoh 2003). Foraging theories postulate that a consumer species selectively feeds upon species that provide it the highest net energy intake per unit effort (Emlen 1966, Macarthur \& Pianka 1966) and that if preferred prey become less available, the predators can consume less energetically suitable prey (Emlen 1966, Macarthur \& Pianka 1966, Thierry et al. 2011). Such behavioral flexibility would be crucial for development and survival when facing environmental fluctuations (e.g., in temperature, quality and availability of food). Nonetheless, observations demonstrating the prevalence of this flexible behavior in nature are needed to validate these assumptions (Kondoh 2003, Acheampong et al. 2014, Dell et al. 2014).

Temperature and food quantity and quality have major effects on insect growth and survival. Temperature affects the

Received 22 December 2014; revision accepted 22 April 2015.

${ }^{7}$ Corresponding author; e-mail: olivier.dezerald@gmail.com metabolic rates of ectotherms such as insects, strongly governing development patterns, survival, reproduction, and many other aspects of population dynamics (Visser \& Both 2005, Logan et al. 2006, Régnière et al. 2012). Hence, physiological constraints and metabolic demands should rise with global warming, pervasively altering the functioning of entire communities (Petchey et al. 1999, 2010, Brown et al. 2004, Woodward et al. 2010, Yvon-Durocher et al. 2011). When not living in microsites that buffer exposure to environmental changes, mobile insects use sensory tools (e.g., antennae) to detect thermal fluctuations and move to thermally optimal habitats. Compared with physiological traits, behavioral traits may allow for more ecological flexibility toward thermal fluctuations by triggering faster responses (e.g., avoidance, mitigation) to unsuitable conditions.

The resources used by insects vary widely in quality (nutritional value) and availability (e.g., density, biomass, and/or distribution in space and time). Insects can quickly respond to suboptimal food conditions by preferentially selecting food of high nutritional quality or by increasing intake rates (Mitra \& Flynn 
2005). Sub-optimal food conditions are particularly stressful for insects that must store sufficient resources during larval feeding stages to support the development, dispersal, and reproduction of adults, non-feeding adults in particular. The effects of temperature or food fluctuations on individual physiology and behavior are well-studied in herbivorous species (Behmer 2009). However, there have been few attempts to disentangle such effects in predaceous insects (but see Traniello et al. 1984).

Toxorbynchites culicids are well-known biocontrol agents against container-inhabiting mosquito larvae, although their effectiveness has been questioned because their biology and behavior are insufficiently characterized (Collins \& Blackwell 2000, Focks 2007). Some predatory larvae of Toxorbynchites sp. inhabiting the water-filled rosettes of tank bromeliads (Bromeliaceae) forage at the water-air interface, where they prey on aquatic and terrestrial invertebrates (mosquito larvae and ants, respectively) throughout their larval life span (Linley 1995, Campos \& Lounibos 2000). For instance, T. haemorrboidalis (Fabricius) is common in bromeliad axils as well as Heliconia flower bracts in northern South America (Lounibos et al. 1987). Owing to their small catchment and high terrestrial:aquatic surface ratio, bromeliad pools contain suitable model organisms to assess if temperature-induced changes in metabolic demands alter predatory behavior as well as aquatic versus terrestrial prey selection in top predators. Assuming that (1) the metabolic demands of individuals increase with increasing temperature (Trpis 1972), and (2) T. haemorrboidalis selectively feeds on the species (i.e., either mosquito larvae or ants) that provides the highest energy intake under ambient conditions, we tested the hypothesis that the preference for a prey species would remain unchanged with experimental warming, despite an increase in prey consumption.

\section{METHODS}

STUdy SPECIES AND SAMPLE COLLECTION.-In French Guiana, the larvae of $T$. haemorrboidalis are among the largest and most numerically dominant predators (including odonate and tabanid larvae) in the aquatic communities dwelling in tank bromeliads. These larvae grow through four instars and are considered generalist predators that can exhibit cannibalistic behavior.

To test how temperature:diet interactions affect $T$. haemorrhoidalis survival, we conducted experiments in the laboratory in Kourou, French Guiana, from March to July 2013. We sampled all of the aquatic insects (i.e., T. haemorrhoidalis and other Culicidae larvae) from two tank bromeliad species. We sampled Aechmea mertensii Schult.f. (Bromeliaceae), which obligatorily grows on ant gardens (AGs, Benzing 2000) inhabited by either the ants Camponotus femoratus Fabr. (Formicinae) or Neoponera goeldii Forel (Ponerinae) near the Petit-Saut dam $\left(05^{\circ} 03^{\prime} 30.0^{\prime \prime} \mathrm{N} ; 52^{\circ} 58^{\prime} 34.6^{\prime \prime}\right.$ W). We sampled Aechmea aquilega Griseb. (Bromeliaceae) near the city of Sinnamary $\left(05^{\circ} 22^{\prime} 42.9^{\prime \prime} \mathrm{N} ; 52^{\circ} 57^{\prime} 11.9^{\prime \prime} \mathrm{W}\right)$. Contrary to A. mertensii, A. aquilega is facultatively associated with ants, which build their nests within the leaf rosette. To collect aquatic invertebrates from the tanks, we carefully emptied the wells in each plant by sucking out the water using $10-\mathrm{ml}$ and $50-\mathrm{ml}$ pipettes with the end trimmed to widen the orifice (Jabiol et al. 2009, Jocque et al. 2010). We pooled all of the invertebrate samples regardless of origin.

GuT CONTENTS.-We used gut contents to quantitate the relative importance of the various prey items. After collection in the field, we preserved 30 third/fourth instar larvae in formalin (4\%) for subsequent dissection ( $N=17$ from $A$. mertensii and $N=13$ from $A$. aquilega). We collected late instar larvae because, within invertebrate food webs, the largest individuals within a species have the greatest effect on energy flows (Céréghino 2006). We determined the diet of $T$. haemorrboidalis larvae by dissecting the entire gut, and analyzing it with a microscope (Optiphot-2 Nikon $^{\circledR}$, Garden City, NY, US). Most prey items could be identified and enumerated by comparing chitinous fragments (e.g., head capsules or the legs of insects and the setae of Oligochaeta) with specimens of tank bromeliad invertebrates archived in our collection (University of Toulouse 3, France.).

ResourCe PREFERENCE AND PREDATION BEHAVIOR.-Examination of the gut contents suggested that ants constituted a substantial fraction of T. haemorrhoidalis' diet, but mosquito larvae are the most abundant prey species at our study site (Dézerald et al. 2014). Therefore, we conducted two-way choice tests on 30 third and fourth instar $T$. haemorrboidalis larvae $(N=9$ from $A$. mertensii and $N=21$ from $A$. aquilega; body size $=8.29 \pm 0.11$, $N=30$ ) by offering them $C$. levior ants (taken from AGs; body size $=1.72 \pm 0.03, N=30$ ) and Wyeomyia pertinans mosquito larvae (body size $=3.91 \pm 0.17, N=30$ ). We placed $T$. haemorrhoidalis larvae into separate plastic tubes (diameter $=3 \mathrm{~cm}$; height $=7 \mathrm{~cm}$; water volume $=40 \mathrm{ml}$ ) behind a rigid plastic strip (width $=3 \mathrm{~cm}$; length $=8 \mathrm{~cm}$ ) at ambient temperature (water temperature $=25 \pm 0.5^{\circ} \mathrm{C}$ ). On the other side of this strip, we placed one mosquito larva in the water column and one ant on the surface of the water. The plastic strips prevented premature attacks while adding the prey. After $10 \mathrm{sec}$, we pulled the strip out of each tube and recorded the predator's vertical position in the water column, which prey species was attacked first, total number of attacks per prey item, and which prey was consumed. After a deadly attack, the other prey was removed. If no attack occurred after $15 \mathrm{~min}$, we removed both prey. Finally, we repeated the two-way choice tests for each individual predator at 3-day intervals. We did not feed the larvae between the two tests.

A total of 90 tests (30 tested individuals across three successive tests) were validated. Before testing for a potential prey preference, we verified if $T$. haemorrboidalis individuals displayed learning in their predatory behavior. We used an extension of generalized linear models (GLMs), generalized estimation equations (GEEs), because GEEs accommodate repeated observations on the same individual (Liang \& Zeger 1986). In GEEs, an association structure between subsequent observations or measures from the same individual must be specified. We recorded behavioral observations every 3 days (time-ordered dataset), so we selected an auto-regressive correlation structure (Zuur et al. 2009). We tested the null hypothesis that the number of attacks 
toward ants and mosquito larvae in the three successive tests are the same. Conversely, if attacks increased or decreased across successive tests it would suggest learning had occurred. In these models, the response variables were the species of prey that was first attacked, the total number of attacks directed toward ants or mosquitoes, and the prey species that overcame deadly attacks. For each response variable, two separate models were used for ants and mosquitoes. The three successive tests were entered as a categorical (three levels) explanatory variable. Finally, we carried out proportion tests with Yates' continuity correction for one sample on the total number of first attacks, the total number of attacks, and the total number of deadly attacks directed toward ants and mosquitoes. We conducted these proportion tests on either all or each successive test separately depending on the GEE results. The latter analyses allowed us to assess if predatory larvae preferred either ants or mosquitoes, while taking potential learning into account.

EFFECT OF TEMPERATURE AND DIET ON PREY CONSUMPTION AND DEVELOPMENT.-We collected 63 first instar T. haemorrboidalis from the field $(N=11$ from $A$. mertensii and $N=52$ from $A$. aquilega) and placed them into separate plastic tubes (diameter $=3 \mathrm{~cm}$; height $=7 \mathrm{~cm}$ ) in the laboratory at an ambient temperature $\left(25 \pm 0.5^{\circ} \mathrm{C}\right)$. We fed them with mosquito larvae (W. pertinans) until they reached third instar. Then, we randomly conditioned the larvae at three different water temperatures. We selected experimental temperature according to a pilot study, where we placed small data loggers (iButtons $@$; Maxim Corporation, Dallas, Texas, U.S.A.) in the central reservoir of two bromeliads located in forested and open areas for 2 weeks during the dry season, monitoring temperatures every hour. Temperatures oscillated between 22 and $33^{\circ} \mathrm{C}$ with a mean of $24.6 \pm 0.06^{\circ} \mathrm{C}$ and $28.3 \pm 0.08^{\circ} \mathrm{C}( \pm \mathrm{SE}, N=425)$ in the forested and open areas, respectively. Therefore, we placed tubes in large plastic trays filled with water at $25 \pm 0.5^{\circ} \mathrm{C}, 29 \pm 0.5^{\circ} \mathrm{C}$ and $33 \pm 0.5^{\circ} \mathrm{C}$ (21 tubes per tray, one T. haemorrhoidalis per tube). We set the water temperature in the trays using 50-watt electric immersion heaters for aquariums (Visitherm Eco ${ }^{\circledR}$, http://www.aquariumsystems.eu/). Finally, we provided different food items to fourth instar larvae (Fig. 1). For each temperature treatment, we fed seven larvae ad libitum with either mosquito larvae or ants, and provided the remaining seven individuals with ants and mosquito larvae in equal proportions. In the latter treatment, if the T. haemorrboidalis ate all of the mosquito larvae or ants, we added more individuals from both taxa. To prevent the ants from escaping and for the sake of consistency among treatments, we put the tube caps on top of all tubes (unscrewed) although the ants were rarely able to leave the water surface and climb the tube walls. We recorded elements of the predator's development every 3 days for the rest of their aquatic cycle, namely: days spent in the trays, if the larvae pupated or died, number and type of prey consumed, and mean consumption rate. We calculated the latter variable as the number of prey available for predatory larvae minus the number of live prey in the tubes after 3 days, divided by the total number of days spent in the trays. Since prey occasionally died due to unknown causes (no apparent signs of 'wasteful' killing behavior by predatory larvae), we replaced both eaten and dead prey. At the end of the experiment, we collected the T. haemorrhoidalis pupae, and oven-dried them at $60^{\circ} \mathrm{C}$ for $48 \mathrm{~h}$ to obtain dry mass.

DATA ANALYSIS. - To determine the overall effect of diet and temperature on T. haemorrboidalis, we used GLMs with the time needed to reach the final state (i.e., dead or pupa), and the final state as response variables. As the time spent in trays could partially confound negative or positive effect on survival, we utilized two distinct models, i.e., one model for development time, and one for final state. The explanatory variables were diet, tempera-

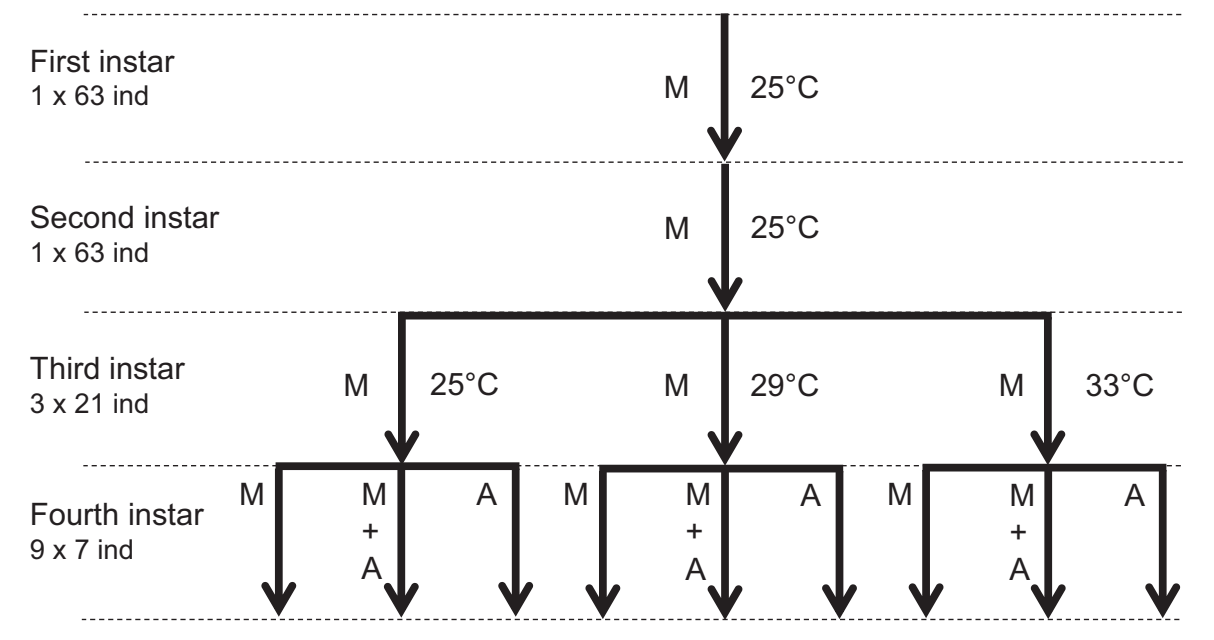

FIGURE 1. Schematic representation of the experimental design of the temperature:diet interactions. On the left is the number of Toxorbynchites haemorrhoidalis individuals within each larval stage (from one to four instars) according to the different temperature and food treatments. T. haemorrhoidalis larvae were provided with either mosquito larvae (i.e., Wyeomyia sp.), ants (Crematogaster levior) or both $(\mathrm{M}, \mathrm{A}, \mathrm{M}+\mathrm{A})$ in three temperature treatments $\left(25,29\right.$, and $\left.33^{\circ} \mathrm{C}\right)$. 
ture, and their interactions (two factorial variables with three levels). Since the time needed to pupate is expressed in days (count-based data) and the final state is a binomial variable, we fit the models with Poisson and binomial families. We conducted an Akaike information criterion (AIC)-based selection on the GLMs and graphically assessed the validation of the final models. To test the hypothesis that increasing temperature positively affects consumption rates, we conducted a Kruskal-Wallis test with the mean consumption rates of mosquito larvae or ants as entered variables and temperatures as explanatory variables. To further evaluate the effects of both diet and temperature on predator development, we assessed changes in consumption habits over time. For each T. haemorrhoidalis larva, we regressed the number of prey consumed every 3 days against time. We used GEEs with an auto-regressive correlation structure as described for the choice tests. Moreover, for T. haemorrhoidalis raised with both mosquitoes and ants, we used two separate models. We assessed the temperature effect on slope estimates within a given diet treatment using a Kruskal-Wallis test. We compared the consumption of either mosquitoes or ants, when the larvae were provided with either one or both prey species using a Wilcoxon rank-sum test. We evaluated all statistical analyses at 95\% CI using R v. 2.15.2 (R Development Core Team 2012) with the add-on Geepack v. 1.1-6 package for GEE analysis (http://cran.r-project.org/doc/packages). We graphically assessed model validation (GLMs, and GEEs), evaluated the normality of residuals using Shapiro tests, and performed additional chi-square tests on the deviance and residual degrees of freedom for goodness-of-fit of the models (GLMs). We present the results as means $\pm \mathrm{SE}$ throughout.

\section{RESULTS}

Gut CONTENTS.-Overall, 20 of the 30 dissected T. haemorrhoidalis had identifiable prey fragments in their gut. Ants contributed on average $46.7 \pm 0.12$ percent of the diet. Other frequent prey were Wyeomyia spp. (Culicidae; $13.3 \pm 0.07 \%$ of the prey items) and Tanypodinae larvae (Chironomidae; $13.3 \pm 0.1 \%$ ). Less frequent prey were Tanytarsus (Chironomidae), Bezzia sp., and Forcipomyiinae (Ceratopogonidae) (6.7 $\pm 0.07 \%$ each), as well as Culex spp. (Culicidae $3.3 \pm 0.03 \%$ ) and Telmatoscopus sp. (Psychodidae $3.3 \pm 0.03 \%)$.

RESOURCE PREFERENCE AND PREDATION BEHAVIOR.-Toxorbynchites haemorrhoidalis larvae spend most of their time resting and breathing at the water-air interface. A gentle tap on their plastic tube makes them swim downwards. Doing so after the strips were removed positioned the predatory larvae at the bottom of their tubes. The mosquito larvae behaved similarly when on the surface of the water, whereas the ants moved frantically on the surface of the water trying to reach the tube walls. Toxorbynchites haemorrhoidalis larvae responded quickly to the presence of ants by swimming toward them in a series of undulating backward movements. They then angled themselves at about $45^{\circ}$ to the water's surface, and progressively adjusted their lateral position to face the ants. Once within striking distance, the predatory larvae curled up, swam vertically, seized the ants in their mandibles, and drowned them. Due to the ants' frantic movements and the air bubbles trapped by the ant setae that made them float, the predators struggled to maintain their position in the water column while breathing through their siphons. By contrast, when preying on mosquito larvae, T. haemorrhoidalis larvae acted as ambush predators. The predatory larvae remained motionless at the bottom of the tubes until the mosquito larvae swam close by. Then, they launched a lateral strike, grasped their aquatic prey, and swallowed the mosquito larvae within a few minutes.

The number of first attacks directed toward ants or mosquito larvae did not differ significantly across the three successive choice tests according to the GEEs (Table 1; ants: Wald $=0.07$, $P=0.79$; mosquito larvae: Wald $=0.8, P=0.371)$. Overall, ants and mosquito larvae overcame 53 and 23 first attacks, respectively, and the proportion test indicates that T. haemorrhoidalis larvae were significantly more attracted by ants than by mosquito larvae (Fig. 2A; Pearson $\left.\chi^{2}=11.1, \quad P=0.0009\right)$. However, whereas ants suffered a significantly higher total number of attacks for the first choice test compared to mosquito larvae (Pearson $\chi^{2}=60.1, P<0.0001$ ), this number decreased signifi-

TABLE 1. Results of the generalized estimation equations (GEEs). Models were generated for three response variables: the prey species that was first attacked, the total number of attacks and the prey species that overcame the deadly attack. The prey were either mosquito larvae or ants.

\begin{tabular}{|c|c|c|c|c|}
\hline Response variable & Models & Estimate $\pm \mathrm{SE}$ & Wald & $P$ \\
\hline \multirow[t]{8}{*}{ First attack } & Ants & & & \\
\hline & Intercept & $0.49 \pm 0.38$ & 1.66 & $<0.0001$ \\
\hline & Second test & $4.72 \mathrm{e}-16 \pm 0.54$ & 0.00 & 1.00 \\
\hline & Third test & $-0.01 \pm 0.54$ & 0.07 & 0.79 \\
\hline & Mosquitoes & & & \\
\hline & Intercept & $-1.34 \pm 0.46$ & 8.59 & 0.003 \\
\hline & Second test & $0.38 \pm 0.62$ & 0.37 & 0.541 \\
\hline & Third test & $0.55 \pm 0.61$ & 0.8 & 0.371 \\
\hline \multirow[t]{8}{*}{ Number of attacks } & Ants & & & \\
\hline & Intercept & $1.05 \pm 0.21$ & 25.27 & $<0.0001$ \\
\hline & Second test & $0.02 \pm 0.36$ & 0.00 & 0.947 \\
\hline & Third test & $-0.66 \pm 0.3$ & 4.76 & 0.029 \\
\hline & Mosquitoes & & & \\
\hline & Intercept & $-1.28 \pm 0.35$ & 13.62 & 0.0002 \\
\hline & Second test & $0.32 \pm 0.46$ & 0.48 & 0.488 \\
\hline & Third test & $0.49 \pm 0.43$ & 1.25 & 0.263 \\
\hline \multirow[t]{8}{*}{ Deadly attacks } & Ants & & & \\
\hline & Intercept & $-1.34 \pm 0.46$ & 8.59 & 0.003 \\
\hline & Second test & $0.85 \pm 0.60$ & 2.03 & 0.154 \\
\hline & Third test & $1.14 \pm 0.59$ & 3.69 & 0.055 \\
\hline & Mosquitoes & & & \\
\hline & Intercept & $-1.34 \pm 0.46$ & 8.59 & 0.003 \\
\hline & Second test & $0.12 \pm 0.63$ & 0.1 & 0.753 \\
\hline & Third test & $0.38 \pm 0.62$ & 0.37 & 0.541 \\
\hline
\end{tabular}




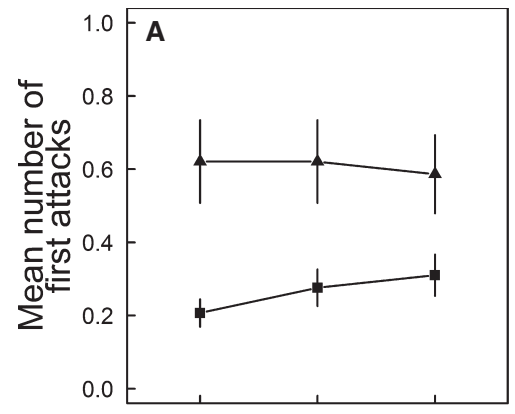

Day 1 Day 4 Day 7

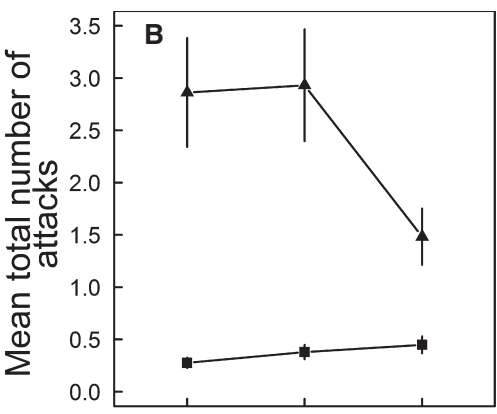

Day 1 Day 4 Day 7

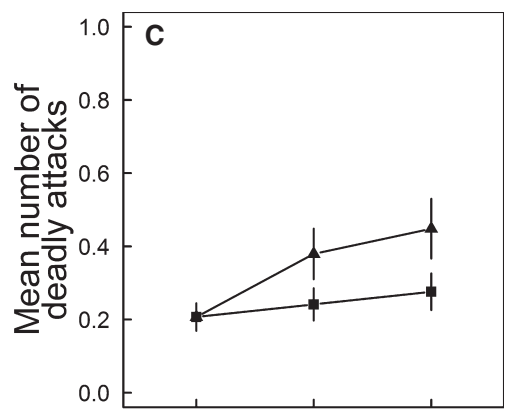

Day 1 Day 4 Day 7

FIGURE 2. Distribution of attacks in three successive trials by 30 Toxorbynchites haemorrboidalis larvae leading to the consumption of ants (triangles) or mosquito larvae (squares) in two-way choice tests. The mean number of primary attacks (A), the mean total number of attacks (B), and the mean number of deadly attacks (C) are shown (error bars $=\mathrm{SE}$ ). One test per T. baemorrboidalis larva was run at 3-day intervals for a total of the three events.

cantly upon the third test (Table 1 ; Wald $=4.76, P=0.029)$. For the third test, the total number of attacks did not differ significantly between the ants and mosquito larvae (Fig. 2B; Pearson $\left.\chi^{2}=0.78, P=0.377\right)$. These results indicate that the predatory larvae did not favor or reject a given prey after being presented with the other prey in earlier events, but T. haemorrhoidalis was more effective at capturing ants during the third test compared to the first one. Finally, T. haemorrhoidalis did not significantly increase the number of deadly attacks toward ants compared to those directed toward mosquito larvae (Table 1; ants: Wald $=3.69, \quad P=0.055 ; \quad$ mosquito larvae: $\quad$ Wald $=0.37$, $P=0.54)$. However, in all choice tests the numbers of deadly attacks were significantly higher toward ants than mosquitoes (Pearson $\chi^{2}, \chi^{2}=7.9, P=0.005$ ). Together, these results suggest that T. haemorrhoidalis larvae were significantly more attracted by ants at first sight, that over time they learned to better manipulate ants, and that the number of deadly attacks was significantly higher for ants than mosquitoes.

EFFECT OF TEMPERATURE AND DIET ON PREY CONSUMPTION AND DEVELOPMENT.-The relationship between the number of days spent in the trays and diet varied significantly with respect to temperature (Table 2; $P<0.0001$ ). Toxorbynchites haemorrhoidalis larvae spent less time in the trays when raised with mosquito larvae as food than when provided with ants only $(-0.66 \pm 0.08$, $z=-8.08, P<0.0001)$, and they spent less time at higher temperatures $\quad(-0.7 \pm 0.08, \quad z=-8.46, \quad P<0.0001)$. For instance, predatory larvae spent on average $32.7 \pm 2.3$ and

TABLE 2. Results of the generalized linear models (GLMs) testing the relationship between the number of days spent in trays (Days) and if the Toxorhynchites haemorrhoidalis larvae pupated or died (Final State) as a function of diet and temperature. Both explanatory variables are factors with three levels. Diet (M): T. haemorrhoidalis larvae raised with mosquito larvae only; Diet (M-A): larvae raised with both mosquito larvae and ants; Temp (29): larvae raised at $29^{\circ} \mathrm{C}$; Temp (33): larvae raised at $33^{\circ} \mathrm{C}$. Only the final models are represented, but Akaike information criterion (AIC) are provided for the final model and full models. Dev/rDev $=$ Deviance and residual deviance.

\begin{tabular}{|c|c|c|c|c|c|c|c|}
\hline & Estimate $\pm \mathrm{SE}$ & $Z$ & $P$ & df & Dev/rDev & $\chi^{2}$ & $\mathrm{AIC}$ \\
\hline Days & & & & & & & $949.2(1008)$ \\
\hline Intercept & $4.14 \pm 0.05$ & 87.152 & $<0.0001$ & & & & \\
\hline Diet $(\mathrm{M})$ & $-0.66 \pm 0.08$ & -8.08 & $<0.0001$ & 2 & $113 / 683$ & $<0.0001$ & \\
\hline Diet $(M-A)$ & $-0.11 \pm 0.07$ & -1.55 & 0.12 & & & & \\
\hline Temp (29) & $-0.12 \pm 0.07$ & -1.77 & 0.08 & 2 & $34 / 650$ & $<0.0001$ & \\
\hline Temp (33) & $-0.7 \pm 0.08$ & -8.46 & $<0.0001$ & & & & \\
\hline Diet (M): Temp (29) & $0.05 \pm 0.12$ & 0.47 & 0.641 & 4 & $67 / 583$ & $<0.0001$ & \\
\hline Diet (M-A): Temp (29) & $0.18 \pm 0.1$ & 1.84 & 0.07 & & & & \\
\hline Diet (M): Temp (33) & $0.88 \pm 0.12$ & 7.2 & $<0.0001$ & & & & \\
\hline Diet (M-A): Temp (33) & $0.53 \pm 0.11$ & 4.82 & $<0.0001$ & & & & \\
\hline Final State & & & & & & & $53.32(56.72)$ \\
\hline Intercept & $0.92 \pm 0.59$ & 1.55 & 0.12 & & & & \\
\hline Temp (29) & $0.88 \pm 0.97$ & 0.91 & 0.36 & 2 & $6 / 47$ & 0.047 & \\
\hline Temp (33) & $-1.2 \pm 0.8$ & -1.5 & 0.13 & & & & \\
\hline
\end{tabular}


$39.1 \pm 4.8$ days in the trays at 33 and $25^{\circ} \mathrm{C}$ in the mosquito larvae treatment, whereas, when provided only with ants, predaceous larvae stayed twice as long at lower temperature, spending on average $31.4 \pm 7.5$ and $63.1 \pm 13.2$ days in the trays at 33 and $25^{\circ} \mathrm{C}$ temperatures, respectively. The effect of temperature on the time spent in trays was less marked in the mosquito and in the mosquito-ant diet treatments than in the ant-based diet (Table 2).

All individuals died at the larval stage when fed only ants. This weakened our statistical analyses, so we ran subsequent GLMs without this factor (the diet variable remained two-fold: mosquitoes and both mosquitoes and ants). Finally, we detected a marginal but significant effect of temperature on mortality rates (Table $2 ; \chi^{2}, P=0.047$ ). At high temperature, eight individuals of 14 died $(57 \%)$, whereas only four died at low temperature $(29 \%)$. In summary, increasing temperatures significantly reduced the time spent in trays and the survival of T. haemorrhoidalis, and this effect was exacerbated by an ant-based diet. At low temperatures, all T. haemorrhoidalis larvae (except one that died) developed over a short period of time before emerging when raised only with mosquito larvae as food, whereas they lived twice as long in the trays but they all died before pupation when provided only with ants. At the highest temperature, three individuals died at the larval stage and four were able to emerge when raised only with mosquitoes, while all larvae died over the same time span when fed only with ants.

Temperature had a significant influence on the daily average consumption of mosquito larvae (Kruskal-Wallis test, $\chi^{2}=8.16$, $P=0.017$ ), but not on that of ants (Kruskal-Wallis test, $\left.\chi^{2}=3.04, P=0.22\right)$. A single fourth instar predatory larva could eat up to 339 and 167 third/fourth culicid instars at 33 and $25^{\circ} \mathrm{C}$, respectively (in 67 and $34 \mathrm{~d}$, respectively). By contrast, a single predatory larva could eat up to 41 and 119 ants at 33 and $25^{\circ} \mathrm{C}$, respectively (Fig. 3).

Temperature did not significantly affect the pattern of mean daily prey consumption. Indeed, within a given diet treatment (either raised with a single or both prey species), slopes in the various temperature treatments were not significantly different
(Table 3; Fig. 4; Kruskal-Wallis tests, $0.07<\chi^{2}<2.82$, $0.244<P<0.965)$. By contrast, diet significantly changed consumption rates. For instance, when fed only with mosquito larvae, T. haemorrhoidalis larvae greatly increased their prey consumption over time throughout the fourth instar stage (average slope estimates in this treatment $=1.53 \pm 0.33 \mathrm{SE}$ ), eating up to 10 mosquito larvae per day for several days before pupation or death. However, the average slope of mosquito larva consumption dropped to $0.3 \pm 0.07$, when the predatory larvae were raised with both mosquito larvae and ants, representing around three mosquito larvae per day before pupation or death, and the slopes are significantly different (Table 3; Fig. 4A; Wilcoxon Rank Sum test, $\mathrm{W}=409, P<0.0001)$. Contrastingly, when provided only with ants, consumption was negatively correlated with time $(-0.42 \pm 0.1)$; i.e., $<1$ ant per day on average before dying. Nonetheless, when provided with both mosquito larvae and ants, the consumption of ants was less negatively correlated $(-0.1 \pm 0.02)$; thus, predatory larvae ate more than one ant per day before pupation or death. The slopes for the consumption of ants in the different treatments were significantly different (Table 3; Fig. 4B; Wilcoxon rank sum test, $\mathrm{W}=98.5$, $P=0.012)$. Finally, regardless of the temperature, the dry mass of $T$. haemorrhoidalis pupae fed with both mosquito larvae and ants $(3.17 \pm 0.9 \mathrm{mg} ; N=13)$ was significantly lower than the dry mass of pupae fed with mosquito larvae only $(4.48 \pm 1.1 \mathrm{mg} ; N=16 ; \mathrm{W}=161, P=0.01)$.

\section{DISCUSSION}

Gut contents indicate that T. haemorrboidalis larvae living in tank bromeliads in the wild prey upon both small ant species (i.e., Crematogaster spp.) and aquatic mosquito larvae. Paine (1934) was the first to observe that $T$. inornatus is attracted by any disturbance generated on the surface of the water by aerial insects. Subsequently, Breland (1949) suggested that terrestrial insects may be an important food source for Toxorbynchites larvae when other prey are unavailable. Our choice tests demonstrated that T. haemorrboidalis larvae preferentially selected terrestrial prey and
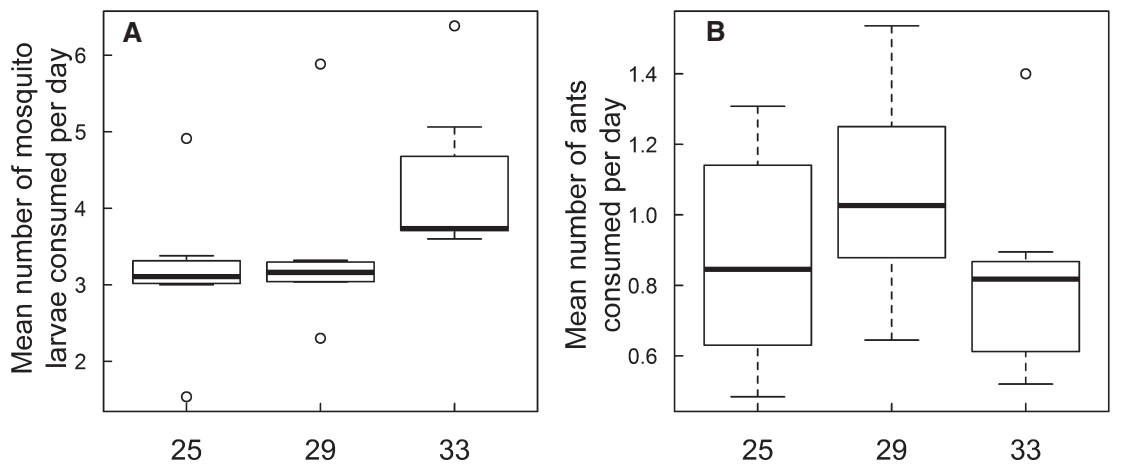

FIGURE 3. Mean number of mosquito larvae (A) and ants (B) consumed per day at 25,29 , and $33^{\circ} \mathrm{C}$. Temperature had a significant effect on the mean daily consumption of mosquito larvae (A) but did not influence ant consumption (B) (Kruskal-Wallis test, $\chi^{2}=8.16, P=0.017$ and $\chi^{2}=3.04, P=0.22$ for $\mathrm{A}$ and $\mathrm{B}$, respectively). 
TABLE 3. Average slope estimates and standard errors calculated from models where the number of prey consumed by Toxorhynchites haemorrhoidalis larvae was regressed against time. The slopes are distributed according to nine treatments: three different temperatures (average temperature in Celsius) $x$ three different diets. Toxorhynchites haemorrhoidalis larvae were provided with either mosquito larvae or ants alone, or with both mosquito larvae and ants. When $\mathrm{T}$. haemorrhoidalis larvae were provided with both mosquito larvae and ants, two slopes were estimated for each prey consumed. The results of Kruskal $-W a l l i s$ tests $(K-W)$ and Wilcoxon ranke sum tests (W) are presented.

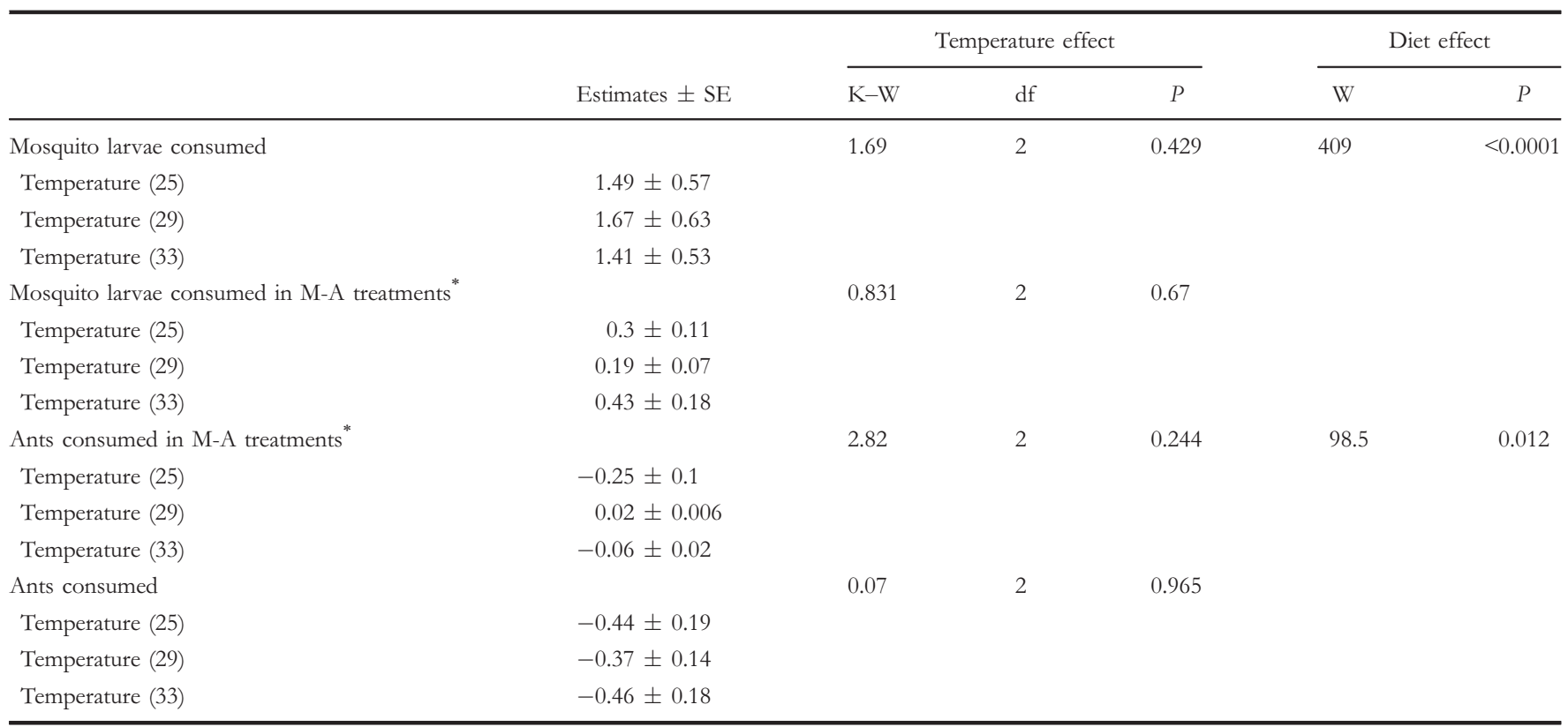

*M-A represents treatments where predatory larvae were provided with both mosquito larvae and ants.
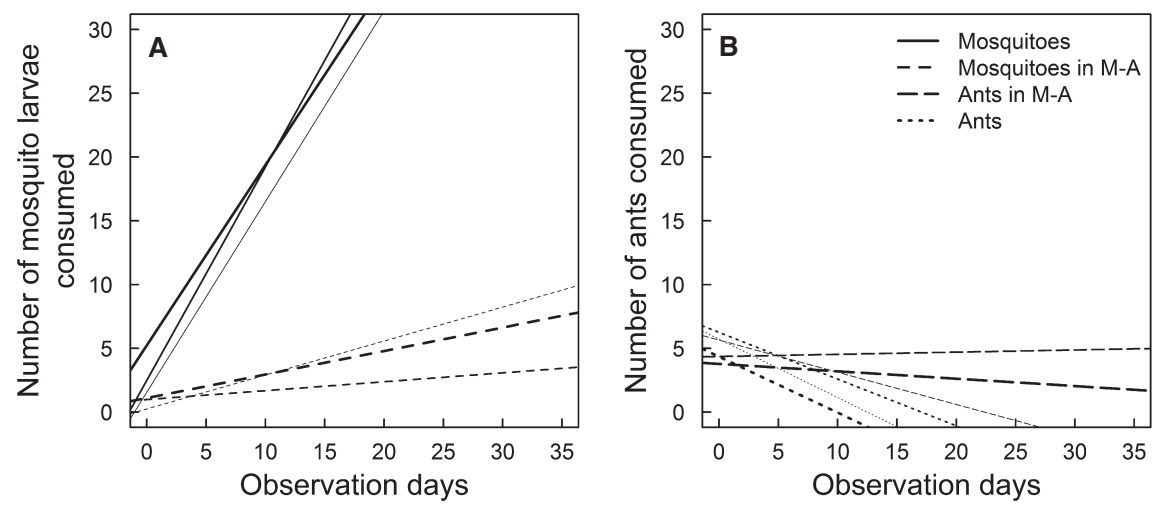

FIGURE 4. Mean slope estimates of the number of mosquito larvae (A) and ants (B) consumed over time according to three temperature and diet treatments. Increasing slope thickness represents an increase in temperature treatment $\left(25,29\right.$, and $\left.33^{\circ} \mathrm{C}\right)$. M-A represents treatments where Toxorbynchites haemorrhoidalis larvae were provided with both mosquito larvae and ants (see Table 3 for SE). Note that observations ( $x$ axis) were made every 3 days. To obtain daily consumption one needs to divide the consumption by three.

displayed an active predatory behavior toward ants that included several discrete steps spanning from prey localization to prey manipulation and consumption. This behavior indicates that these larvae are able to process spatial information so as to optimize the acquisition of terrestrial resources (Linley 1995). Neither active (with ants) nor ambush-like predation (with mosquito larvae) behaviors were affected by temperature manipulation in subsequent experiments.
As insects are ectotherms, their metabolic activity generally increases with temperature and they are capable of adjusting their consumption habits accordingly (Ward \& Stanford 1982). Here, T. haemorrboidalis showed a significant increase in the daily consumption of mosquito larvae in relation to the temperature gradient generated $\left(25,29\right.$, and $\left.33^{\circ} \mathrm{C}\right)$. Regardless of the time spent in the trays, these predators ate on average 1.6-times more mosquito larvae at $33^{\circ} \mathrm{C}$ than at $25^{\circ} \mathrm{C}$. These observations are in line with 
previous studies about consumption rates by Toxorbynchites spp. (Trpis 1972, Steffan \& Evenhuis 1981, Lounibos et al. 1998) and other culicid species (Lounibos et al. 2002, Reiskind \& Zarrabi 2012). By contrast, T. haemorrhoidalis larvae ate on average 2.7times more ants at $25^{\circ} \mathrm{C}$ than at $33^{\circ} \mathrm{C}$. Indeed, these predatory larvae spent more time in trays at $25^{\circ} \mathrm{C}$ than at $33^{\circ} \mathrm{C}$, although their mean daily consumption of ants was not significantly affected by temperature. These data represent the first reported consumption rates of terrestrial prey by aquatic invertebrate predators in relation to water temperature. Temperature significantly influenced the survival of the late instar larvae through its interaction with diet. Indeed, when fourth instar T. haemorrhoidalis larvae were fed only with ants, the individuals died after 31 days at $33^{\circ} \mathrm{C}$ on average, compared to 63 days at lower temperatures. The larval life span of this genus varies from 10 to 91 days depending on the species, water temperature, and prey density (Steffan \& Evenhuis 1981). Although mortality among predatory larvae was high at $33^{\circ} \mathrm{C}$, suggesting that this temperature is at the edge of the thermal tolerance range for T. haemorrhoidalis, the adults oviposit in both forested and sun-exposed areas in French Guiana (pers. obs., see also Jabiol et al. 2009); thus, the larvae are naturally exposed to extreme temperatures.

Our results also showed that the adverse effect of temperature on the metabolic demands of $T$. haemorrboidalis was exacerbated by consuming ants. Pupation was never achieved at any temperature on an ant-only diet. It is possible that the ants provided few nutritional rewards compared to the energetic cost of manipulating and digesting them, and/or that they did not provide chemical compounds required to trigger pupation. Assuming that $T$. haemorrboidalis is well-adapted to preying upon terrestrial insects and that this behavior has not been counter selected, there must be a threshold of toxicity (e.g., the digestive enzymes and alkaloid compounds of ants' venom) beyond which predators cannot survive. The effect of food toxicity has been well-studied in herbivorous species but less so in predators (Gutierrez-Ibanez et al. 2007, Behmer 2009, Jensen et al. 2011).

Generalist predators are believed to feed on a wide variety of resources to obtain a nutritional balance (Behmer 2009). In this study, regardless of temperature, the dry mass of $T$. haemorrhoidalis pupae fed with both mosquito larvae and ants was significantly lower than the dry mass of pupae fed with mosquitoes only. For many holometabolous insects, reproduction is closely linked to the amount of resources accumulated during the larval stages (Boggs \& Freeman 2005). However, the extent to which the morphological and physiological characteristics (e.g., the dry mass of pupae and adults, or wing length; see Reiskind \& Zarrabi 2012) of pupae are related to adult fitness in Toxorbynchites spp. deserves further attention. Learning to distinguish suitable from unsuitable prey coupled with effective foraging techniques can greatly improve fitness (Cunningham et al. 1998, Ishii \& Shimada 2010). Learning has been reported in several insect taxa, and can even continue after metamorphosis in holometabolous insects (Dukas 2008, Kawecki 2010). Here, we report that ants suffered a higher total number of attacks in the first choice test compared to mosquito larvae, and that this number decreased significantly in the third test. These results suggest that T. baemorrboidalis individuals were more effective at capturing ants on the third day than on the first one, and we cautiously posit that learning may improve foraging efficiency in predatory larvae. In the presence of both mosquito larvae and ants, fourth instar T. haemorrhoidalis decreased their consumption of mosquitoes and shifted to ants, whatever the temperature (see Fig. 4). We thus suggest that throughout its fourth instar stage (long-term basis) and regardless of thermal conditions, T. haemorrhoidalis cannot distinguish energetically suitable (mosquito larvae) from unsuitable (ants) prey. We conclude that the stimulus produced by ants on the surface of the water influenced the predator more than the adverse outcome of an ant-based diet. This study provides further evidence that prey activity and/or detectability is one of the main drivers of diet in aquatic invertebrate predators rather than a predator's active choice (Peckarsky \& Penton 1989, Sih 1993). Other unexpected consumption habits have been reported by Eggert and Wallace (2007), who showed that some aquatic detritivores preferentially fed upon leaf detritus although the surface biofilm of microbes was more nutritionally suitable. The prevalence of such unexpected behaviors in nature therefore requires greater attention given their importance in helping to predict the effects of disturbances on communities via species' responses.

The sophistication of $T$. haemorrhoidalis foraging strategies also indicates that it is well-adapted to prey on terrestrial insects. It may be that under natural conditions (i.e., in the water-filled rosettes of the bromeliads) $T$. haemorrboidalis preferentially consumes terrestrial prey more nutritious than ants, so that the observed hunting strategy could increase growth. Field experiments manipulating terrestrial invertebrate inputs could test the preference for ants versus other terrestrial species in nature. A related question concerns the frequency at which terrestrial resources enter the aquatic food web. Nevertheless, this study suggests that predatory larvae in bromeliad reservoirs are frequently exposed to ants and preferentially feed on them, despite the higher abundance and constant availability of aquatic prey. The trophic level at which allochtonous resources enter the system is also of great importance as it may enhance either the topdown or bottom-up effects that pervade the entire food web (Jefferies 2000). In tank bromeliads that host T. haemorrboidalis larvae which preferentially feed on terrestrial insects, aquatic invertebrates (notably mosquito larvae) may indirectly benefit from predation release. In conclusion, higher temperatures negatively affect the survival of T. haemorrhoidalis through interaction with diet, but do not change $T$. haemorrhoidalis preference for terrestrial prey despite their adverse influence on survival. The potentially synergistic effects of biotic and abiotic stressors (e.g., sub-optimal diet and thermal conditions) on species-specific behavioral traits may hamper our ability to predict community-wide responses to environmental changes.

\section{ACKNOWLEDGMENTS}

We are grateful to Frederic Petitclerc and Stanislas Talaga for technical help, Andrea Yockey-Dejean for proofreading the manu- 
script, and the Laboratoire Environnement de Petit Saut for furnishing logistical assistance. This study has benefited from an 'Investissement d'Avenir' grant managed by the Agence Nationale de la Recherche (CEBA, ref. ANR-10-LABX-0025). OD's financial support was provided by a $\mathrm{PhD}$ fellowship from the French CNRS and the Fond Social Européen. We also wish to thank two anonymous reviewers for providing insightful comments on the manuscript.

\section{LITERATURE CITED}

Acheampong, E., I. Hense, And M. A. St. John. 2014. A model for the description of feeding regulation by mesozooplankton under different conditions of temperature and prey nutritional status. Ecol. Model. 272: 84-97.

BeHmer, S. T. 2009. Insect herbivore nutrient regulation. Annu. Rev. Entomol. 54: $165-187$.

Benzing, D. H. 2000. Bromeliaceae: Profile of an adaptative radiation. Cambridge University Press, Cambridge, UK.

Boggs, C. L., and K. D. Freeman. 2005. Larval food limitation in butterflies: Effects on adult resource allocation and fitness. Oecologia 144: 353361.

Breland, O. P. 1949. The biology and the immature stages of the mosquito, Megarbinus septentrionalis Dyar \& Knab. Ann. Entomol. Soc. Am. 42: $38-47$.

Brown, J. H., J. F. Gillooly, A. P. Allen, V. M. Savage, and G. B. West. 2004. Toward a metabolic theory of ecology. Ecology 85: 1771-1789.

Campos, R. E., AND L. P. Lounibos. 2000. Natural prey and digestion times of Toxorbyncbites rutilus (Diptera: Culicidae) in southern Florida. Ann. Entomol. Soc. Am. 93: 1280-1287.

CÉrÉGHINO, R. 2006. Ontogenetic diet shifts and their incidence on ecological processes: A case study using two morphologically similar stoneflies (Plecoptera). Acta Oecol. 30: 33-38.

Coldins, L. E., AND A. BlaCkiweld. 2000. The biology of Toxorbynchites mosquitoes and their potential as biocontrol agents. Biocontr. News Inform. 21: $105 \mathrm{~N}-116 \mathrm{~N}$.

Cunningham, J. P., S. A. West, and D. J. Wright. 1998. Learning in the nectar foraging behaviour of Helicoverpa armigera. Ecol. Entomol. 23: 363-369.

Dell, A. I., S. Pawar, and V. M. Savage. 2014. Temperature dependence of trophic interactions are driven by asymmetry of species responses and foraging strategy. J. Anim. Ecol. 83: 70-84.

Dézerald, O., S. Talaga, C. Leroy, J.-F. Carrias, B. Corbara, A. Dejean, AND R. CÉRÉGHINo. 2014. Environmental determinants of macroinvertebrate diversity in small water bodies: Insights from tank-bromeliads. Hydrobiologia 723: 77-86.

DukAs, R. 2008. Evolutionary biology of insect learning. Annu. Rev. Entomol. 53: $145-160$.

Eggert, S. L., AND J. B. Wallace. 2007. Wood biofilm as a food resource for stream detritivores. Limnol. Oceanogr. 52: 1239-1245.

EmLen, J. M. 1966. The role of time and energy in food preference. Am. Nat. 100: 611-617.

Focks, D. A. 2007. Toxorbynchites as biocontrol agents. J. Am. Mosq. Control Assoc. 23: 118-127.

Gutierrez-Ibanez, C., C. A. Villagra, and H. M. Niemeyer. 2007. Pre-pupation behaviour of the aphid parasitoid Apbidius ervi (Haliday) and its consequences for pre-imaginal learning. Naturwissenschaften 94: 595-600.

Ishit, Y., AND M. SHIMADA. 2010. The effect of learning and search images on predator-prey interactions. Popul. Ecol. 52: 27-35.

Jabiol, J., B. Corbara, A. Dejean, and R. Céréghino. 2009. Structure of aquatic insect communities in tank-bromeliads in a East-Amazonian rainforest in French Guiana. For. Ecol. Manage. 257: 351-360.

JefFERIES, R. L. 2000. Allochtonous inputs: Integrating population changes and food-web dynamics. Trends Ecol. Evol. 15: 19-22.
Jensen, K., D. Mayntz, S. Toft, D. Raubenheimer, and S. J. Simpson. 2011. Nutrient regulation in a predator, the wolf spider Pardosa prativaga. Anim. Behav. 81: 993-999.

Jocque, M., A. Kernahan, A. Nobes, C. Willians, and R. Field. 2010. How effective are non-destructive sampling methods to assess aquatic invertebrate diversity in bromeliads? Hydrobiologia 649: 293-300.

KAWECKI, T. J. 2010. Evolutionary ecology of learning: Insights from fruit flies. Popul. Ecol. 52: 15-25.

KondoH, M. 2003. Foraging adaptation and the relationship between foodweb complexity and stability. Science 299: 1388-1391.

LiAng, K. Y., AND S. L. Zeger. 1986. Longitudinal data-analysis using generalized linear-models. Biometrika 73: 13-22.

LinLeY, J. R. 1995. Behavior on approach to surface prey by larvae of Toxorbynchites amboinensis and Toxorbynchites brevipalpis (Diptera: Culicidae). J. Med. Entomol. 32: 53-65.

Logan, J. D., W. Wolesensky, And A. Joern. 2006. Temperature-dependent phenology and predation in arthropod systems. Ecol. Model. 196: 471-482.

Lounibos, L. P., J. H. Frank, C. E. Machado-Allison, P. Ocanto, and J. C. NAVARRO. 1987. Survival, development and predatory effects of mosquito larvae in Venezuelan phytotelmata. J. Trop. Ecol. 3: 221-242.

Lounibos, L. P., E. A. Martin, D. Duzak, and R. L. Escher. 1998. Daylength and temperature control of predation, body size, and rate of increase in Toxorbynchites rutilus (Diptera: Culicidae). Ann. Entomol. Soc. Am. 91: 308-314.

Lounibos, L. P., S. Suarez, Z. Menendez, N. Nishimura, R. L. Escher, S. M. O'Connell, And J. R. Rey. 2002. Does temperature affect the outcome of larval competition between Aedes aegypti and Aedes albopictus? J. Vector Ecol. 27: 86-95.

Macarthur, R. H., and E. R. Pianka. 1966. On the optimal use of patchy environment. Am. Nat. 100: 603-609.

Mitra, A., and K. J. Flynn. 2005. Predator-prey interactions: Is 'ecological stoichiometry' sufficient when good food goes bad? J. Plankton Res. 27: 393-399.

Paine, R. W. 1934. The introduction of Megarbinus mosquitoes into Fiji. Bull. Entomol. Res. 25: 1-31.

Peckarsky, B. L., And M. A. Penton. 1989. Mechanisms of prey selection by stream-dwelling stoneflies. Ecology 70: 1203-1218.

Petchey, O. L., U. Brose, and B. C. Rall. 2010. Predicting the effects of temperature on food web connectance. Philos. Trans. R. Soc. B Biol. Sci. 365: 2081-2091.

Petchey, O. L., P. T. McPhearson, T. M. Casey, and P. J. Morin. 1999. Environmental warming alters food-web structure and ecosystem function. Nature 402: 69-72.

R Development Core Team (2012). R: A language and environment for statistical computing. R Foundation for Statistical Computing, Vienna, Austria. ISBN 3-900051-07-0, URL http://www.R-project.org/.

Régnière, J., J. Powell, B. Bentz, and V. Nealis. 2012. Effects of temperature on development, survival and reproduction of insects: Experimental design, data analysis and modeling. J. Insect Physiol. 58: 634-647.

Reiskind, M. H., And A. A. Zarrabi. 2012. Is bigger really bigger? Differential responses to temperature in measures of body size of the mosquito, Aedes albopictus. J. Insect Physiol. 58: 911-917.

SiH, A. 1993. Effects of ecological interactions on forager diets: Competition, predation risk, parasitism and prey behaviour. Diet selection: An interdisciplinary approach to foraging behaviour. In R. N. Hughes (Ed.). Diet selection: An interdisciplinary approach to foraging behaviour, pp. 183-211. Blackwell Scientific Publications, Cambridge University Press, Cambridge, UK.

Steffan, W. A., and N. L. Evenhuis. 1981. Biology of Toxorbyncbites. Annu. Rev. Entomol. 26: 159-181.

Thierry, A., A. P. Beckerman, P. H. Warren, R. J. Willitams, A. J. Cole, and O. L. Petchey. 2011. Adaptive foraging and the rewiring of size-structured food webs following extinctions. Basic Appl. Ecol. 12: 562-570. 
Traniello, J. F. A., M. S. Fujita, and R. V. Bowen. 1984. Ant foraging behavior: Ambient temperature influences prey selection. Behav. Ecol. Sociobiol. 15: 65-68.

Trpis, M. 1972. Development and predatory behavior of Toxorbynchites brevipalpis (Diptera: Culicidae) in relation to temperature. Environ. Entomol. 1: 537-546.

Visser, M. E., And C. Both. 2005. Shifts in phenology due to global climate change: The need for a yardstick. Proc. R. Soc. B Biol. Sci. 272 . 2561-2569.

Ward, J. V., And J. A. Stanford. 1982. Thermal responses in the evolutionary ecology of aquatic insects. Annu. Rev. Entomol. 27: 97-117.
Woodward, G., D. M. Perkins, and L. E. Brown. 2010. Climate change and freshwater ecosystems: Impacts across multiple levels of organization. Philos. Trans. R. Soc. B Biol. Sci. 365: 2093-2106.

Yvon-Durocher, G., J. M. Montoya, M. Trimmer, and G. Woodward. 2011. Warming alters the size spectrum and shifts the distribution of biomass in freshwater ecosystems. Glob. Change Biol. 17: 1681-1694.

Zuur, A. F., E. N. Ieno, N. J. Walker, A. A. Saveliev, and G. M. SMith. 2009. Mixed effects models and extensions in ecology with R. Mixed effects models and extensions in ecology with R, p. 574 . 